\title{
Um e outro: Ferenczi e a epistemologia'
}

\section{Leonardo Câmara* \\ Regina Herzog}

Programa de Pós-Graduação em Teoria Psicanalítica, Universidade Federal do Rio de Janeiro (UFRJ), Rio de Janeiro, RJ, Brasil

Resumo: $O$ presente artigo se propõe investigar a maneira como Ferenczi refletiu acerca de algumas questões epistemológicas ao longo de sua obra para produzir a figura do "utraquismo". Esta noção vai se prestar, em seu pensamento, a estabelecer um método de interlocução da psicanálise com saberes estranhos a ela - notadamente a biologia -, visando promover a ampliação do campo teórico psicanalítico. Esta ampliação vai propiciar a criação de conceitos e, consequentemente, o enriquecimento das reflexões sobre os modos de fazer clínica. Nestes termos, o utraquismo concretiza a tomada de posição epistemológica de Ferenczi, que consistiu em uma recusa a se aliar de forma rígida ao idealismo ou ao materialismo - correntes filosóficas que ele coloca como as duas atitudes fundamentais do homem, no que concerne ao conhecimento.

Palavras-chave: epistemologia, Ferenczi, metodologia, utraquismo, materialismo.

\section{"O devaneio não é a catástrofe virtual em que se inicia o conhecimento?"}

(René Thom, citado por Sabourin, 1988, p. 93)

Sándor Ferenczi ocupa uma posição particular no quadro de referências da teoria psicanalítica: seu nome é lembrado, sobretudo, por suas inovações técnicas e suas reflexões sobre o trauma. As polêmicas pesquisas empreendidas por ele nestes dois campos possuem um alcance tão espantoso que ainda hoje não foi esgotado todo o potencial que elas detêm. Entretanto, e Freud aponta isso, sua obra comporta outras contribuições que não se limitam a apenas estas duas linhas de pesquisa. Atentos a esta observação, pretendemos, com o presente trabalho, lançar luz sobre uma região negligenciada ou, ao menos, pouco explorada da obra ferencziana: suas reflexões epistemológicas e metodológicas. É notável como essas questões perpassam o discurso do autor em momentos diferentes de sua produção, sendo lícito dizer que elas foram alvo de uma preocupação constante de sua parte. Longe de terem se dado em um campo puramente abstrato, elas se encontram intimamente articuladas à experiência clínica e são continuamente repensadas para dar conta dos desafios daí advindos. $\mathrm{O}$ estudo destes problemas, tais como trabalhados por Ferenczi, é particularmente proveitoso para refletir-se com maior apuro acerca de seus estilos de pensamento e de composição teórica.

Assim, o objetivo deste artigo é trazer para a cena os parâmetros que levaram Ferenczi a elaborar e reformular o quadro de referências a que se reportou rei-

1 Os autores agradecem a Jô Gondar pela leitura cuidadosa e crítica deste trabalho.

* Autor correspondente: 1cpcamara@gmail.com teradamente quando defrontado com os problemas epistemológicos e metodológicos da psicanálise. Ele ocupou-se constantemente com o lugar desta última no quadro dos saberes, buscando explicitar seu próprio posicionamento. Sem desconsiderar o dualismo entre ciências da natureza e ciências do espírito que conformava o campo do conhecimento, Ferenczi se propôs a pensar a epistemologia das ciências da mente a partir de dois eixos de referência. $\mathrm{O}$ primeiro deles consistindo no materialismo em oposição ao idealismo (também designado por ele como solipsismo), e o segundo eixo compreendendo a oposição monismo/dualismo. Apesar de poder haver (dependendo da perspectiva que se adote) uma relação muito íntima entre, de um lado, materialismo e monismo e, do outro, idealismo e dualismo, o próprio Ferenczi, no curso de suas investigações, decompõe tais afinidades ao descrever o percurso ontogenético da interface do sujeito com a realidade (Ferenczi, 1913a/1992, 1913b/1992). Defendemos que a forma como este problema é colocado e trabalhado no quadro geral de referências estabelecido por Ferenczi, bem como suas tentativas de solucioná-lo, forneceram as condições para criar os seus posicionamentos epistemológico e metodológico particulares, que culminaram na figura conceitual do utraquismo (Ferenczi, 1924b/1993).

\section{A crise do materialismo}

Desde muito cedo Ferenczi assume a tese de que o conhecimento humano, ao longo da História, oscila entre duas tendências, o materialismo e o idealismo, sendo este movimento regido pelas ordens políticas e religiosas hegemônicas de cada época (Ferenczi, 1899). Esta oposição, tida como usual no âmbito da filosofia, já se encontra presente em "O espiritismo", primeiro artigo publicado pelo autor. A partir dela, Ferenczi estabelece o território onde 
pode se situar para realizar a crítica aos saberes psicológicos e psiquiátricos da época e, subsequentemente, conceber uma linha de fuga. Adiantando uma das consequências deste último ponto, vale dizer que o autor vislumbrará na psicanálise, e depois na bioanálise, a possibilidade de superar a oscilação do eixo materialismo-idealismo (Ferenczi, 1909a/1991, 1924b/1993). Bem entendido que esta superação será balizada por sua própria perspectiva epistemológica, fortemente alicerçada na experiência clínica. Porém, antes de nos determos nesta questão, comecemos por descrever o que o autor compreendia por materialismo e idealismo.

A perspectiva idealista se apresenta notavelmente menos invocada por Ferenczi em suas comunicações. É sobretudo no estudo dos mecanismos de introjeção e projeção que o idealismo (ou solipsismo) é mais amiúde apresentado, enquanto contraponto indissociável do materialismo. Sublinhe-se que há uma indistinção, por parte deste autor, no uso dos termos "idealismo" e "solipsismo", sendo assim compreendidos como sinônimos dentro de seu léxico. Para ele, o idealismo, que confere "à subjetividade um lugar fundamental" (Herzog \& Gondar, 2011), pode ser compreendido do seguinte modo:

O solipsismo constitui a última palavra, logicamente irrefutável, da pura intelectualidade do ego sobre a relação com outros indivíduos; segundo essa teoria, nunca se pode colocar no mesmo plano a realidade dos outros seres humanos ou do mundo externo e as próprias experiências pessoais; podese somente considerar os outros como fantasias mais ou menos animadas ou projeções. (Ferenczi, 1926/1993, p. 374)

Lorin (1992) observa que a distância com que Ferenczi trata desta corrente se explica pelo fato de ele julgá-la afastada daquilo "que vivem concretamente os homens que ele trata" (p. 55), e insuficiente para "dar conta dos sofrimentos do ser humano" (p. 55). Alicerçado no desprezo tanto pela experiência concreta quanto pela base científica objetiva, o idealismo alemão orientado por Kant é suplantado pelo materialismo (Ferenczi, 1899), tornando-se este último a corrente filosófica dominante do meio científico no século XIX e de pelo menos o primeiro terço do século XX (Ferenczi, 1923a/1993, 1933/1992).

O materialismo designa toda concepção que tem por princípio o primado da matéria. Segundo esta doutrina, tudo é matéria ou é produto e/ou efeito da mesma (ComteSponville, 1998). O avanço das ciências naturais no século XIX, que trazem em seu bojo novas concepções sobre o que é e como funciona a matéria viva, estimula o triunfo do materialismo sobre o idealismo em diversos campos do conhecimento. Por exemplo, a descoberta e formulação de modelos baseados em evidências materiais encontradas no organismo possibilitaram a concepção de que as atividades mentais seriam efeitos da matéria. Neste sentido, o materialismo entra frontalmente em choque com o idealismo: se para este último o pensamento é uma entidade autônoma e primeira, para o materialismo o pensamento é secundário, sendo antes determinado pelo corpo (Comte-Sponville, 1998). Não por acaso este exemplo foi evocado: a psicologia materialista é o objeto privilegiado no discurso ferencziano. $\mathrm{O}$ autor se reporta fundamentalmente a esta área do conhecimento, quando apresenta em seu discurso a figura do materialismo.

Notadamente orientada pelo e para o molde das ciências naturais (Ferenczi, 1912d/1991), a psicologia de vertente materialista tem seu escopo de estudo reduzido à observação e mensuração de fenômenos psíquicos elementares, ligados basicamente às esferas da motricidade $\mathrm{e}$ da sensopercepção (Ferenczi, 1909a/1991). Erigida em concepções importadas de outras disciplinas - principalmente a química, física e biologia -, a psicologia científica de vertente materialista baseia-se firmemente no paradigma experimental e na observação (Ferenczi, 1912d/1991). Nesta, os eventos psíquicos são concebidos como movimentos de partículas ou de estruturas moleculares no seio do tecido nervoso (Ferenczi, 1899). Isto significa dizer que o materialismo impõe, como fato moral, que a totalidade dos fenômenos psíquicos deve ser explicada no registro da materialidade, tal como esta é, evidentemente, compreendida pelas ciências naturais. Enfatizemos que Ferenczi compõe e se refere a uma figura particular da filosofia materialista, fundamentada nas perspectivas da psicologia científica. É certo que, em determinados momentos de sua obra, ele chegue a escrever uma observação ou outra sobre o materialismo dialético, por exemplo (Ferenczi, 1922a/1992). Entretanto, a representação de materialismo que nos importa, e que ele se dispõe a usar em seu discurso, é a que se descreveu até aqui.

Na virada do século Ferenczi se mostra particularmente esperançoso com a possibilidade do materialismo tornar-se menos rígido e dogmático com a aceitação da teoria evolucionista e, por consequência, com a concepção de um paralelismo psicofísico (Ferenczi, 1900). Todavia, posteriormente, ele se situa de forma clara e inequívoca como um crítico desta psicologia que se encontra "sob o império de concepções materialistas e mecanicistas" (Ferenczi, 1909a/1991, p. 44). Suas comunicações assumem um tom de denúncia que busca apontar uma crise nas ciências do espírito (Lorin, 1992). Para ele, o fracasso em encontrar correlações entre doença mental e alterações anatômicas se devia ao fato de "que sabemos tão pouco, no dia de hoje, sobre o princípio anatomopatológico das psiconeuroses quanto sobre as relações materiais do funcionamento mental em geral" (Ferenczi, 1909a/1991, p. 44). A consequência disso é que a psicologia científica encontra-se desconectada não apenas da experiência da loucura, como também da vida humana cotidiana. Seu diagnóstico é pessimista:

A parte dos fenômenos psíquicos que pode ser medida, colocada em fórmulas matemáticas, abordada pela experimentação, é uma fração tão pequena e elementar da vida psíquica que, sob o efeito da cor- 
rente materialista, a psicologia caiu na categoria de um domínio tributário da fisiologia sensorial condenada à esterilidade, podemos afirmá-lo com toda a certeza, há várias décadas. (Ferenczi, 1912d/1991, pp. 233-234)

Se alguém forneceu algum corpo conceitual organizador diante de uma infértil "acumulação incoerente de informação" (Ferenczi, 1900), foi Fechner e Wundt (Ferenczi, 1909a/1991). A concentração da pesquisa científica nos fatos psíquicos elementares deixa de lado um amplo espectro de eventos psíquicos complexos, como " $\mathrm{os}$ problemas do conhecimento do homem, do estudo do caráter, [dos] conflitos psíquicos e seus modos de liquidação, [e dos] efeitos passageiros ou duradouros das impressões psíquicas" (Ferenczi, 1912d/1991, p. 234, grifos nossos). Neste sentido, não é difícil calcular que a psicologia de orientação materialista apresenta uma "total falência no [que tange ao] tratamento das neuroses" (Ferenczi, 1933/1992, p. 86). Torna-se urgente a criação de uma teoria para superar o ponto frágil que, aos olhos de Ferenczi, é inaceitável: a ineficiência clínica.

\section{A situação da psicanálise}

$\mathrm{Na}$ produção científica de Ferenczi da primeira década do século XX se encontra, de forma marcante, a denúncia à psicologia fundamentada em um programa epistemológico baseado em uma perspectiva eminentemente materialista. Não obstante, também vislumbramos, esparsas em seus escritos da época, certas linhas de fuga diante dessa configuração. Se as consequências dessa última são principalmente a infertilidade teórica e a desconexão com a práxis clínica, as linhas que escapam de tal crise oferecem a possibilidade renovada de explorar as zonas do psiquismo até então ignoradas pela psicologia científica materialista. A este respeito Ferenczi vê, por exemplo, o ocultismo como um foco de resistência e contestação a um racionalismo dogmático (Ferenczi, 1899; Lorin, 1992); a teoria da evolução como o detentor de um novo paradigma do pensamento científico (Ferenczi, 1900); a literatura, com seu "olhar ingênuo mas penetrante" (Ferenczi, 1909a/1991, p. 48), como precursora da ciência na descrição dos fatos psicológicos (Ferenczi, 1909a/1991; Lorin, 1992); a hipnose como um procedimento terapêutico promissor (Lorin, 1992); e, por fim, a psicanálise como um movimento que assegura uma potente renovação no âmbito tanto da pesquisa em psicologia quanto do tratamento psíquico (Ferenczi, 1909a/1991). Nosso interesse é mostrar como Ferenczi busca posicionar a psicanálise em relação a certas questões epistemológicas. Podemos depreender da leitura de uma série de artigos publicados em $1912^{2}$ sua preocupação em situar a psicanálise em relação à fillosofia,

2 Referimo-nos aqui aos textos "O conceito de introjeção", "A figuração simbólica dos princípios de prazer e de realidade no mito de Édipo" e "Filosofia e psicanálise". assim como, uma vez situada, entender sua função perante a última. Para sermos mais precisos, podemos dizer que, se Freud busca situar a psicanálise em relação à filosofia, sempre mantendo-se em uma posição de suspeita em relação a esta (Birman, 2003), Ferenczi almeja o contrário: situar a filosofia em relação à psicanálise.

A posição do autor é firme: a psicanálise é uma ciência e, enquanto tal, não apenas se encontra distinta da filosofia como deve manter-se independente em relação à mesma. É importante marcar que estamos trabalhando aqui com um determinado modo pelo qual Ferenczi entende e pensa a ciência e a relação desta com as outras categorias de pensamento. Segundo ele, "as duas disciplinas, filosofia e psicologia, obedecem a princípios diferentes, e as duas têm interesse em permanecer separadas" (Ferenczi, 1912c/1991, p. 216). A vitalidade e a potência da psicanálise, com respeito à pesquisa científica, só podem ser preservadas se não for submetida a tal ou qual sistema filosófico (Ferenczi, 1912c/1991), mantendo-se antes imparcial no seu processo de elaboração científica (Ferenczi, 1923b/1993). Neste sentido, sendo uma "ciência jovem", a psicanálise deve abster-se tanto de ser integrada a uma concepção de mundo quanto ela própria construir uma Weltanschauung. O perigo de a psicanálise ser seduzida por estes empreendimentos seria o de comprometer a sua objetividade e potência criativa. Em outras palavras, tornando-se um sistema conceitual fechado, remetido e afiliado a uma corrente filosófica, não seriam toleradas observações e informações que contradissessem os conceitos e as relações entre conceitos já firmados e consolidados (Ferenczi, 1912c/1991). Por isso Ferenczi se confessa particularmente simpático ao agnosticismo que, de acordo com suas palavras, "reconhece honestamente a impossibilidade de resolver problemas últimos e por isso não é um sistema filosófico verdadeiramente fechado" (Ferenczi, 1912c/1991, pp. 216-217). Apenas em 1923, ao assinar o prefácio da edição húngara de Além do princípio de prazer e ainda impactado com a nova doutrina das pulsões, ele observa que a psicanálise se encontra suficientemente madura para produzir "uma concepção de mundo inteiramente nova e independente de tudo o que existia antes" (Ferenczi, 1923b/1993, p. 223). Isto porque ela erigiu, neste meio tempo, a metapsicologia, este "vasto sistema científico que não para de se expandir progressivamente" (Ferenczi, 1924a/1993, p. 225).

Se a psicanálise é compreendida como uma ciência por Ferenczi, as diferentes correntes filosóficas são consideradas, ao lado da religião, da ficção, das obras de arte e mesmo das variadas correntes políticas, "produções psíquicas" que podem ser investigadas pela psicologia (Ferenczi, 1912c/1991, 1913a/1992, 1922a/1993). Esta posição encontra-se em sintonia com o projeto freudiano de elucidar certas correlações profundas entre a religião, o complexo de Édipo, a neurose obsessiva e o sentimento de culpa, empreendido no mesmo período e culminado na publicação de Totem e Tabu (Freud, 1913/2006). Ferenczi parece situar-se ao largo deste procedimento freudiano que empreende uma relação analógica entre uma psicopatologia e um sistema 
materializado na cultura através da sublimação. Seu interesse, como veremos adiante, está focado precisamente na localização dos mecanismos psíquicos que servem de fundamento tanto para o funcionamento mental quanto para o sistema de pensamento. Isto não o impede, naturalmente, de invocar determinada categoria psicopatológica como forma de correlacioná-la com um sistema de pensamento.

No início da década de 1910 podemos constatar uma sutil e, não obstante, notável mudança em sua perspectiva epistemológica: a reflexão filosófica e a produção artística cedem seus respectivos lugares cativos à ciência encarnada pela psicanálise, tal como este autor a compreende. Aqueles se tornam objetos científicos que, como os demais fatos psíquicos, estão submetidos às leis que a "ciência" do inconsciente pode isolar e descrever. A consequência desta concepção é importante: a psicanálise se torna um instrumento de investigação que tem a potência de elucidar as bases psicológicas da relação estabelecida pelo sujeito com as diferentes formas de conhecimento. É através da experiência eminentemente clínica que Ferenczi se vê autorizado a levar adiante tal empreendimento, retomando as figuras do materialismo e idealismo.

Esta retomada implica, como veremos, uma redescrição do quadro de referências que lhe serve de mapa para visualizar suas concepções epistemológicas. Tal função atribuída à psicanálise se dá imediatamente - isto é, já em 1912. Nesta época, Ferenczi tem em mãos dois conceitos de alto valor heurístico: a introjeção e a projeção (Ferenczi, 1912a/1991). Partindo da premissa de ser possível "igualmente classificar os sistemas metafísicos em sistemas introjetivos e projetivos" (Ferenczi, 1912a/1991, p. 182), Ferenczi dota de uma explicação psicológica a forma como os dois movimentos - materialismo e idealismo - se dão, sendo elas, lembremos, as duas atitudes fundamentais do homem no que concerne à produção de conhecimento (Ferenczi, 1899).

A corrente filosófica do idealismo é pensada como uma produção psíquica que tem sua genealogia no funcionamento exacerbado do processo de introjeção (Ferenczi, 1912c/1991). Este é um mecanismo psíquico básico, paradigmático da neurose, cuja função é anexar ao território do eu as representações que remetem ao objeto sexual, de maneira que este possa ser investido libidinalmente pelo sujeito (Câmara, 2012). Segundo Ferenczi, é apenas quando há esta integração do outro à esfera de interesses do eu que o amor objetal encontra condições de se realizar (Ferenczi, 1912c/1991). Assim, o idealismo, que concebe as coisas do mundo externo como manifestações do eu individual, é uma produção psíquica que remete e ao mesmo tempo simboliza o modo de funcionamento da introjeção - esta consistindo, por sua vez, no trabalho psíquico que busca converter as coisas do mundo externo em propriedades pertencentes ao território do eu. Ora, no processo de desenvolvimento do sentido de realidade do sujeito, a fase introjetiva é designada por Ferenczi como sendo a mais arcaica, correlacionando-se ao sentimento de onipotência mágica da criança (Ferenczi, 1913b/1992). Partindo deste raciocínio, concebe o idealismo como a "volta a um infantilismo egocêntrico" (Ferenczi, 1926b/1993, p. 399), fruto de uma fixação em determinado ponto no desenvolvimento do sentido de realidade. $\mathrm{O}$ mundo externo se configura como uma mera manifestação de um eu supremo: o mundo é uma alucinação que remete, em todos os seus matizes, ao próprio sujeito ou, melhor, ao eu-prazer. Ferenczi promove assim um curioso pareamento, no qual o idealismo aloca-se ao lado da introjeção, da neurose, da onipotência, do subjetivismo e do princípio do prazer.

O materialismo, por sua vez, nada mais é que uma formação psíquica que remete ao mecanismo de projeção, paradigmático da paranoia. A projeção é pensada como um processo de conversão de um elemento emocional subjetivo em um elemento perceptual objetivo (Ferenczi, 1909b/1991). Em outras palavras, ela consiste em expulsar do território do eu um determinado elemento, conferindolhe uma exterioridade e, ao mesmo tempo, posicionando seu agora detentor/observador em um sítio de neutralidade e de afastamento. O materialismo seria assim uma manifestação do mecanismo de projeção, pois "nega o ego, dissolvendo-o completamente no "mundo externo"' (Ferenczi, 1912c/1991, p. 215). A propósito do desenvolvimento do sentido de realidade, a projeção estaria mais afastada da onipotência e mais próxima da realidade, sendo fruto de uma maior complexidade da relação do sujeito com o mundo externo e de um maior reconhecimento daquilo que não faz parte do seu eu ${ }^{3}$. Se em 1912 a projeção é correlacionada ao materialismo, no ano seguinte aquele mecanismo passa a ser intimamente relacionado à ciência. Para Ferenczi (1913b/1991), "[o] sentido da realidade atinge o seu apogeu na ciência, na qual, em contrapartida, a ilusão de onipotência cai para o seu nível mais baixo" (p. 49). Neste sentido, parece lícito entender que Ferenczi situa a ciência no registro do materialismo, concebendo ambos como resultado do mecanismo mais essencial de projeção. Fica assim estabelecido o seguinte pareamento: materialismo, projeção, paranoia, condicionalidade (este enquanto abandono da onipotência), objetivismo e princípio de realidade. Ora, se o materialismo é identificado como um projeto de conhecimento mais próximo da realidade, Ferenczi então se situa, de maneira insidiosa e não declarada, mais simpático ao materialismo, apesar de manter-se em uma posição crítica em relação a tal visão de mundo.

A partir destas considerações, a psicanálise consegue dissecar e demonstrar as linhas fundamentais que determinam, psicologicamente, a formação dos sistemas filosóficos bem como a afiliação de tal ou qual indivíduo às mesmas. É neste sentido que Ferenczi situa não a psicanálise em relação à filosofia, mas as filosofias em relação à psicanálise. Esta será usada para promover uma verdadeira

3 No artigo "Consciência e desenvolvimento", publicado em 1900, Ferenczi afirma que o idealismo seria, tal como o movimento romântico alemão, um arrebatamento de juventude que, com a maturidade, seria abandonado em favor do materialismo. Não obstante, tanto uma tendência quanto outra teria, ainda segundo ele, importante função no desenvolvimento tanto do indivíduo quanto da cultura (Ferenczi, 1900). 
análise das variadas correntes filosóficas. No entanto, com a inclusão da ciência no escopo desta investigação da genealogia dos sistemas de pensamento, a própria psicanálise - designada por Ferenczi como uma ciência, enfatizemos -, também deverá ser situada neste enquadre. É o que ocorre em anos posteriores, quando ele coloca que a psicanálise é um retorno ao animismo, no qual são projetados os "próprios processos e características psíquicas sobre os fenômenos universais" (Ferenczi, 1922/1992, p. 224), mas de maneira cientificamente apurada - isto é, superando o vício do antropomorfismo (1924b/1993). Não obstante, o caráter de autonomia que Ferenczi imprime a esta disciplina lhe dá condições de afirmar que "os dados da psicanálise podem integrar-se a não importa que sistema materialista ou idealista, monista ou dualista" (Ferenczi, 1912c, p. 216), uma vez que a sua afiliação a uma dada vertente filosófica é perfeitamente prescindível.

\section{Um e outro}

Como vimos, a psicanálise representou, para Ferenczi, um ponto de descontinuidade no fluxo das ciências da mente, pois "os médicos, antes da época de Freud, tinham um ponto de vista exclusivo e materialista" (Ferenczi, 1933/1992, p. 89). É necessário entendermos o motivo pelo qual Ferenczi atribuiu à psicanálise, e posteriormente à metapsicologia, este estatuto. Por que, dentre tantas linhas de fuga que emergiram no contexto das psicologias de vertente exclusivamente materialista, só a psicanálise conseguiu sobreviver e tomar viço? Podemos rastrear evidências para responder a esta pergunta já em um de seus primeiros textos, no período de sua adesão ao movimento psicanalítico. Vejamos:

Considero que a atividade científica de Freud representa um ponto de mutação na psicologia, pois ele soube renovar o laço entre a ciência e a psicologia da vida, e tirar partido dos tesouros da psicologia que não tinham sido aproveitados e explorados. (Ferenczi, 1909a/1991, p. 45)

Em sua visão, a psicanálise empreende a renovação do laço entre dois estilos de abordagem em relação à psicologia, distanciando-se assim do extremismo - perigoso, acrescentemos - que representaria a adesão radical a uma ou outra. Perigoso porquanto o extremismo leva à hipostasia e à infertilidade no campo da produção de conhecimento. $\mathrm{O}$ valor do trecho acima reproduzido não está em mostrar a psicanálise como um movimento centrífugo em relação ao eixo materialismo-idealismo, uma vez que não são estas as categorias invocadas pelo autor. Mas sim o de explicitar o gesto que a psicanálise representa para ele diante da psicologia. Este gesto é aquele que será batizado, anos depois, com o nome de utraquismo, operador metodológico central da bioanálise (Ferenczi, 1924b/1993). Se o utraquismo adquire este estatuto em "Thalassa, ensaio sobre a teoria da genitalidade", não obstante Ferenczi afirma que caberia a Freud o ato inaugural de tal método (Figueiredo, 1999), es- pecificamente quando do empreendimento de construção e elaboração da metapsicologia (Ferenczi, 1922/1992).

Mas afinal o que é utraquismo? Derivado do termo latino utraque, que significa "um e outro" (Figueiredo, 1999), utraquismo é um "modo de trabalho" que consiste em estabelecer relações analógicas entre elementos distintos e pertencentes a campos de saber heterogêneos, com a finalidade de desvendar a significação de determinados processos (Ferenczi, 1924b/1993). Invoquemos um exemplo para tornar mais concreta esta definição. Na primeira parte de seu ensaio sobre a teoria da genitalidade, Ferenczi busca empreender uma pesquisa sobre "a explicação e a significação dos processos do próprio coito" (Ferenczi, 1924b/1993, p. 258) através do uso de analogias retiradas deste campo de saber heterogêneo em relação à psicanálise que é a biologia. Está claro que esta última não é convocada para suprir uma lacuna deixada pela psicanálise, uma vez que a questão do coito em si não foi por ela trabalhada. A biologia é chamada, sim, para participar ativamente de um diálogo com a psicanálise, com o objetivo de testar e levar até às últimas consequências a hipótese de que a significação fundamental do coito é a tentativa de regressão ao útero materno (Ferenczi, 1924b/1993). Gesto semelhante é realizado por Freud ao se munir das experiências de mortalidade de populações de infusórios para testar a hipótese da pulsão de morte (Freud, 1920/2006).

$\mathrm{O}$ utraquismo enquanto método de pesquisa emerge no momento em que a psicanálise, após ter investigado, durante uma longa trajetória, os mecanismos internos "unicamente com base nos dados fornecidos pelos processos psíquicos internos" (Ferenczi, 1923b/1993, p. 224), deparou-se com a pulsão, monumento que marca o limite entre o somático e o psíquico - e entre a psicanálise e a biologia (Freud, 1920/2006). A pulsão, enquanto conceito, estabeleceria até onde se estendem os perímetros do território de pesquisa da psicanálise (Ferenczi, 1923b/1993). O utraquismo visa transbordar e transgredir estes limites, com o intuito de fornecer "certas visões gerais das coisas que a ciência ortodoxa não nos deixara sequer pressentir" (Ferenczi, 1924b/1993, p. 315). É em Thalassa que Ferenczi se vê autorizado a radicalizar o uso deste método - radicalizar a tal ponto que ele próprio se confessa culpado pelo "crime de psicomorfismo", quando do lançamento das pedras para a fundação de sua bioanálise (Ferenczi, 1924b/1993). Este "método de trabalho" localiza-se, portanto, nas bordas do saber psicanalítico e tem como função ética a invocação da alteridade - isto é, de um saber estranho e heterogêneo - para não apenas constituir novos modelos teóricos, como também para provocar uma instabilidade necessária na tessitura conceitual já firmada. Isto porque, em relação à evolução da pesquisa de um determinado domínio científico, "o progresso linear atinge em geral com bastante rapidez um ponto morto que obriga, se se quiser avançar, a prosseguir o trabalho sob um outro ângulo, muitas vezes inteiramente inesperado ou insólito" (Ferenczi, 1922b, p. 177).

De fato, a importância do diálogo da psicanálise com um saber estranho - no caso, a biologia - é justifica- 
da por Ferenczi ao realizar uma pequena discussão sobre seu método. Ele afirma que "geralmente as substâncias são medidas com substâncias de natureza diferente. Assim somos involuntariamente levados a medir a matéria através do imaterial e vice-versa" (Ferenczi, 1924b/1993, p. 257). Neste sentido, o utraquismo revela um processo dialógico que transcende as duas disciplinas: ele concerne também uma interação complexa entre dois eixos de pensamento, as ciências do espírito e as ciências da natureza. Projeto antigo e fortemente investido por Ferenczi, tal como vislumbrado nesta sua comunicação, por exemplo:

Nós, psicanalistas, desejamos ardentemente que se instaure uma colaboração entre a psicologia e as ciências "exatas", como Mach o reclama em seu livro; mas pedimos, em contrapartida, que as ciências exatas apliquem também o nosso método de investigação psicológica aos problemas da psicogênese e não façam uma separação artificial entre os problemas psicológicos que lhe interessam e os outros conteúdos psíquicos. (Ferenczi, 1919/1993, p. 36-37)

A esperança de que este diálogo pudesse efetivamente se realizar levou Ferenczi a vislumbrar aquilo que ele passou a designar como a iatrofilosofia, "na qual os mais variados domínios do conhecimento, em particular as disciplinas relacionadas com as ciências naturais e as ciências do espírito [...] poderão reencontrar-se na ciência médica" (Ferenczi, 1923a/1993, p. 220). Em todo caso, o utraquismo só pode se tornar um procedimento metodológico quando a psicanálise atinge, em seu corpo teórico, um determinado nível de maturação para dialogar, de igual para igual, com as outras ciências. Esta posição é explícita na citação coligida acima (Ferenczi, 1919/1993) e é estritamente levada em consideração em Thalassa: se a biologia coopera com a psicanálise, a psicanálise também é aplicada ao estudo de objetos da ciência biológica, havendo uma transferência dos "conhecimentos e métodos da psicanálise para as ciências naturais" (Ferenczi, 1924b/1993, p. 315). É este gesto que funda a bioanálise - ou a ciência das origens (Abraham, 1962/1995) -, no seio da qual Ferenczi afirma que todo fenômeno biológico manifesto é dotado de um sentido oculto que só pode ser decodificado mediante a interpretação, e que remonta a estratos históricos pretéritos. Em outras palavras, a partir da psicanálise esse autor enuncia que todo fato científico da biologia está circunscrito na linguagem e que o caráter unívoco de descrição de um fato é insuficiente ou incompleto se não forem levadas outras dimensões em consideração. Nesta medida, o utraquismo é um método analógico que visa não a descrição, mas a interpretação - a produção de sentido - de um dado elemento. Ora, o diálogo realizado entre as duas disciplinas se dá sob a luz de uma relação de mutualidade ${ }^{4}$. Um diálogo mútuo

4 Assim como o utraquismo, as noções de anfimixia e de mutualidade condensam formas análogas de relação entre dois elementos estranhos que, de certa maneira, se opõem entre si. Assim, se é lícito dizer que o utra- sim, mas caracterizado às vezes por relações de parasitismo (Figueiredo, 1999) e, em outras, adquirindo a tonalidade de embates catastróficos, como aqueles descritos pelo autor no percurso filogenético de toda a vida orgânica. Há, no utraquismo conforme proposto por Ferenczi, um amálgama de saberes que se entrelaçam, tendo como consequência um perpétuo processo morfogenético, cujo horizonte é a produção de figuras teóricas híbridas (Figueiredo, 1999).

$\mathrm{O}$ utraquismo pode ser expresso como a culminação mais ousada de uma postura epistemológica buscada e assumida por Ferenczi ao longo de sua vida. Esta posição configura-se não como a tentativa de realizar a síntese entre materialismo e idealismo ou monismo e dualismo ou entre as ciências da natureza e do espírito, mas como um movimento oscilatório, sem ter, no entanto, uma ritmicidade pré-determinada. Como se expressou com precisão Abraham (1962/1995), é um movimento de "vai e vem" e, como descreveu Figueiredo (1999), é um "paradoxal movimento de avançar retornando ou de retornar avançando" (p. 129), próprios da violência e intensidade de um embate, em que ambos os polos se entrelaçam para a produção de novos arranjos teóricos. Desta forma, se o utraquismo é um gesto metodológico que não pode ser confundido com um processo de síntese, ele também se mostra como uma superação das psicologias cujo programa epistemológico se identifica com o materialismo. Ora, se em ambos os casos há um empréstimo de conceitos e metáforas de saberes heterogêneos, a psicologia materialista parece ser colonizada a tal ponto por estas metáforas e por certas exigências de uma pretensa cientificidade, que ela perde sua própria singularidade. $\mathrm{O}$ utraquismo, pelo contrário, ao buscar respeitar a consistência dos saberes que se encontram em intercâmbio, mostra-se impossibilitado de permitir um movimento de colonização deste ou daquele saber 5 .

Retomemos novamente o par de opostos que mais nos ocupou neste trabalho - qual seja, o eixo materialismo-idealismo. A partir destas duas categorias, Ferenczi estabeleceu o terreno onde pôde realizar uma observação crítica das tendências teóricas dos saberes de seu tempo (ciências da natureza e ciências do espírito), identificadas como os conteúdos sócio-históricos das duas atitudes do homem em relação ao conhecimento (materialismo e idealismo). Estes, por sua vez, se correlacionavam com as duas formas de interação do sujeito com o mundo (projeção e introjeção). Vislumbrando os limites inerentes tanto de um polo quanto de outro, este autor buscou situar-se em uma posição nômade, sem um referencial fixo, como forma de evitar ou de ao menos escapar de regiões teóricas e técnicas congeladas e inférteis. O utraquismo representa esta tomada de posição cambiante e vacilante por excelência, na qual o sujeito do conhecimento não está imerso em uma

quismo se refere ao plano do método, podemos colocar que a anfimixia se refere ao plano do conceito e a mutualidade, ao plano da clínica.

5 Por analogia, a resultante do utraquismo está para a introjeção da mesma maneira que a formação da psicologia materialista está para a incorporação, conforme estes conceitos são entendidos na teoria ferencziana do trauma, sob influência de Abraham e Torok (Câmara, 2012). 
ou outra corrente, mas sim em uma e outra. Sua lógica não é do "ou", mas do "e". Um dos pontos cardinais deste método que se torna particularmente compreensível a partir do eixo materialismo-idealismo é a inter-relação dinâmica entre o objetivo e o subjetivo, consistindo "em um vai e vem do objeto observado ao sujeito que observa" (Lorin, 1982, p. 114), "aliando metodologicamente a razão à desrazão" (Lorin, 1982, p. 62). Ora, se o trabalho de composição teórica exige rigor e objetividade, a própria formação das ideias que constituem esta composição - assim como a maneira pela qual aquelas ideias se articulam entre si demanda uma livre capacidade imaginativa, circunscrita a um campo fortemente subjetivo, que tenha potência de produzir a "catástrofe virtual" à qual René Thom se referiu na frase que serve como epígrafe do presente artigo. Para Ferenczi, toda reflexão filosófica e toda produção científica teriam que operar dentro deste interjogo entre o objetivo e o subjetivo, a projeção e a introjeção, o princípio de realidade e o princípio de prazer (Ferenczi, 1912b/1991). Assim, em um importante ensaio teórico onde é realizada uma revisão em larga escala de seu corpo teórico, Ferenczi esclarece:

Mais tarde, quando tentei um enfoque crítico do modo de produção atual da ciência, fui levado a supor que a ciência, se quiser realmente manter-se objetiva, deve trabalhar alternadamente como psicologia pura e como ciência pura, que lhe cumpre confirmar a experiência tanto interna quanto externa dos dois pontos de vista - o que implica uma oscilação entre projeção e introjeção. Foi o que denominei o Utraquismo de todo verdadeiro empreendimento científico. Em filosofia, o solipsismo ultraidealista representa a volta a um infantilismo egocêntrico; quanto à concepção psicofóbica puramente materialista, ela corresponde aos exageros da fase de projeção; em contrapartida, o dualismo sustentado por Freud responde plenamente à exigência utraquística. (Ferenczi, 1926/1993, p. 339, itálico no original)

Lembremos que na psicanálise importantes pontos de virada da teoria, que parecem costurar uma trajetória oscilante entre o objetivo e o subjetivo, o racional e o imaginativo, podem portar o risco de adquirir os contornos de uma "especulação forçada" (Freud, 1920/2006), ameaçando o abandono da credulidade que o leitor mantinha até então com o autor (Freud, 1918/2006). Não obstante, os frutos de tais empreitadas mostraram-se, em certos casos, profundamente férteis.

A psicanálise encontra-se nos dias atuais mais uma vez ameaçada por psicologias fortemente identificadas com projetos epistemológicos que Ferenczi qualificaria como materialistas, onde "sujeito" passa a ser equivalente a "cérebro". Ao mesmo tempo, novas formações subjetivas desafiam sua clínica e impelem, diante de uma limitação de resposta da teoria, à necessidade tanto de revisão de modelos quanto de produção de novos aportes teóricos. Desta forma, certas construções consolidadas do saber psicanalítico começam a apresentar perda de vitalidade, tornando-se progressivamente mais distantes da prática clínica cotidiana. Insidiosamente se transformam, assim, em pontos de referência de algo que já foi, mas lentamente não é mais. $\mathrm{O}$ conceito de inconsciente parece dar lugar ao conceito de trauma como operador central da metapsicologia do sujeito contemporâneo; o divã cede seu espaço para o olho no olho e o silêncio do analista não é mais salvaguardado pela transferência. Esta crise traz em sua esteira questões vertiginosas sobre os ditos novos processos de subjetivação e sobre a dissolução das configurações sociais tidas até algumas décadas atrás como profundamente sólidas e arraigadas: os laços sociais parecem ser mediados não mais pelo sentimento de culpa, mas pela vergonha. Diante deste cenário, o gesto objetivado por Ferenczi na figura do utraquismo é particularmente interessante de ser levado em consideração: trata-se de um método de pesquisa que se situa no limite, convocando mundos estranhos à psicanálise para uma colisão, tendo por meta a fecundação de horizontes conceituais. Fecundação cujo objetivo não é apenas produzir instabilidade no conjunto teórico firmado, mas também atravessá-lo, sugerindo linhas de fuga. Se se pode afirmar que o fruto mais radical deste método - Thalassaé um "delírio biológico" (Lacan, 1962-1963/2005), pode-se igualmente dizer que certos empreendimentos realizados na psicanálise nos últimos sessenta anos produziram aquilo que, dentro de uma mesma linha, chamaríamos de "delírios matemáticos". Isso, todavia, não tira o valor heurístico, a função liberadora (Abraham, 1962/1995) e a potência criativa nem de um e nem de outro.

\section{One and other: Ferenczi and the epistemology}

Abstract: This article aims to investigate the manner in which Ferenczi reflected upon some epistemological questions throughout his works in order to produce the figure of "utraquism". This concept will lend itself, in his thinking, to establish a method of dialog between psychoanalysis and knowledge areas unrelated to it - noticeably biology - in order to promote the growth of the psychoanalytical theoretical field. This expansion will favor the creation of new concepts and, therefore, the enrichment of insights about the ways of clinical practice. Accordingly, utraquism embodies Ferenczi's epistemological stance, which was the refusal to rigidly ally to either idealism or materialism - philosophical streams he considers human's two fundamental attitudes regarding knowledge.

Keywords: epistemology, Ferenczi, methodology, utraquism, materialism. 


\section{Un et autre: Ferenczi et l'épistémologie}

Résumé: Le présent article se propose d'investiguer la manière dont Ferenczi a réfléchi sur quelques questions épistémologiques tout au long de son œuvre afin de produire la figure de l'« utraquisme ». Cette notion va se prêter, dans sa pensée, à établir une méthode de dialogue de la psychanalyse avec des savoirs qui lui sont étrangers - notamment la biologie -, envisageant de promouvoir l'élargissement du champ théorique psychanalytique. Cet élargissement va favoriser la création de concepts et, par conséquent, l'enrichissement des réflexions sur les modes de faire la clinique. En ces termes, l'utraquisme concrétise la prise de position épistémologique de Ferenczi, qui a consisté en un refus de s'allier de manière rigide à l'idéalisme ou au matérialisme - les courants philosophiques qu'il considère comme les deux attitudes fondamentales de l'homme, en ce qui concerne la connaissance.

Mots-clés: épistémologie, Ferenczi, méthodologie, utraquisme, matérialisme.

\section{Uno y otro: Ferenczi y la epistemología}

Resumen: Este artículo tiene como objetivo investigar cómo Ferenczi reflexionó acerca de algunas cuestiones epistemológicas en su trabajo para producir la figura del 'utraquismo'. Este concepto se va a disponer, en su pensamiento, al establecimiento de un método de diálogo entre el psicoanálisis y conocimientos extraños a el - en particular la biología - para promover la expansión del campo teórico psicoanalítico. Esta expansión facilitará la creación de conceptos y por lo tanto el enriquecimiento de las reflexiones sobre las maneras de hacer clinica. En consecuencia, el utraquismo encarna la postura epistemológica de Ferenczi, que consistió en la rehusa a aliarse rígidamente al idealismo ó al materialismo - corrientes filosóficas que son, según él, las dos actitudes fundamentales del hombre, con respecto al conocimiento.

Palavras-clave: epistemologia, Ferenczi, metodologia, utraquismo, materialismo.

\section{Referências}

Abraham, N. (1995). Apresentação de “Thalassa”. In N. Abraham, M. Torok, A casca e o núcleo (pp. 19-27). São Paulo, SP: Editora Escuta. (Trabalho original publicado em 1962)

Birman, J. (2003). Freud e a filosofia. Rio de Janeiro, RJ: Jorge Zahar.

Câmara, L. (2012). Do descrédito (desmentido) à catástrofe: a teoria ferencziana do trauma (Monografia). Instituto de Psicologia, Universidade Federal do Rio de Janeiro, Rio de Janeiro.

Comte-Sponville, A. (1998). Matérialisme (verbete). In S. Aurox (dir.), Encyclopédie philosophique universelle: Les notions philosophiques (pp. 1553-1557). Paris: Presses Universitaires de France.

Ferenczi, S. (1899). El espiritismo. Recuperado de Instituto de Desarrollo Psicológico INDEPSI: http://www. indepsi.cl/ferenczi/

Ferenczi, S. (1900). Conciencia y desarrollo. Recuperado de Instituto de Desarrollo Psicológico INDEPSI: http:// www.indepsi.cl/ferenczi

Ferenczi, S. (1991). A respeito das psiconeuroses. In Psicanálise I (pp. 41-56). São Paulo, SP: Martins Fontes. (Trabalho original publicado em 1909a)

Ferenczi, S. (1991). Transferência e introjeção. In Psicanálise $I$ (pp. 77-108). São Paulo, SP: Martins Fontes. (Trabalho original publicado em 1909b)

Ferenczi, S. (1991). O conceito de introjeção. In Psicanálise I (pp. 181-183). São Paulo, SP: Martins Fontes. (Trabalho original publicado em 1912a)
Ferenczi, S. (1991). A figuração simbólica dos princípios de prazer e de realidade no mito de Édipo. In Psicanálise I (pp. 203-211). São Paulo, SP: Martins Fontes. (Trabalho original publicado em 1912b)

Ferenczi, S. (1991). Filosofia e psicanálise. In Psicanálise I (pp. 213-220). São Paulo, SP: Martins Fontes. (Trabalho original publicado em 1912c)

Ferenczi, S. (1991). O conhecimento do inconsciente. In Psicanálise I (pp. 233-237). São Paulo, SP: Martins Fontes. (Trabalho original publicado em 1912d)

Ferenczi, S. (1992). Fé, incredulidade e convicção sob o ângulo da psicologia médica. In Psicanálise II (pp. 2738). São Paulo, SP: Martins Fontes. (Trabalho original publicado em 1913a)

Ferenczi, S. (1992). O desenvolvimento do sentido de realidade e seus estágios. In Psicanálise II (pp. 3953). São Paulo, SP: Martins Fontes. (Trabalho original publicado em 1913b)

Ferenczi, S. (1992). A metapsicologia de Freud. In Psicanálise IV (pp. 223-234). São Paulo, SP: Martins Fontes. (Trabalho original publicado em 1922)

Ferenczi, S. (1993). A psicogênese da mecânica. In Psicanálise III (pp. 31-39). São Paulo, SP: Martins Fontes. (Trabalho original publicado em 1919)

Ferenczi, S. (1993). Psicanálise e política social. In Psicanálise III (pp. 167-170). São Paulo, SP: Martins Fontes. (Trabalho original publicado em 1922a)

Ferenczi, S. (1993). "Psicologia de grupo e análise do ego", de Freud. In Psicanálise III (pp. 177-181). São Paulo, 
SP: Martins Fontes. (Trabalho original publicado em 1922b)

Ferenczi, S. (1993). A psicanálise a serviço do clínico geral. In Psicanálise III (pp. 211-220). São Paulo, SP: Martins Fontes. (Trabalho original publicado em 1923a)

Ferenczi, S. (1993). Prefácio da edição húngara de "Para além do princípio de prazer”. In Psicanálise III (pp. 223224). São Paulo, SP: Martins Fontes. (Trabalho original publicado em 1923b)

Ferenczi, S. (1993). Perspectivas da psicanálise. In Psicanálise III (pp. 225-240). São Paulo, SP: Martins Fontes. (Trabalho original publicado em 1924a)

Ferenczi, S. (1993). Thalassa, ensaio sobre a teoria da genitalidade. In Psicanálise III (pp. 255-325). São Paulo, SP: Martins Fontes. (Trabalho original publicado em 1924b)

Ferenczi, S. (1993). Contra-indicações da técnica ativa. In Psicanálise III (pp. 365-375). São Paulo, SP: Martins Fontes. (Trabalho original publicado em 1926a)

Ferenczi, S. (1993). O problema da afirmação do desprazer. In Psicanálise III (pp. 393-404). São Paulo, SP: Martins Fontes. (Trabalho original publicado em 1926b)

Ferenczi, S. (1992). Influência de Freud sobre a medicina. In Psicanálise IV (pp. 85-96). São Paulo, SP: Martins Fontes. (Trabalho original publicado em 1933)
Figueiredo, L. C. (1999). Palavras cruzadas entre Freud e Ferenczi. São Paulo, SP: Escuta.

Freud, S. (2006). Totem e tabu. In S. Freud, Edição standard das obras psicológicas completas de Sigmund Freud (Vol. 13, pp. 17-162). Rio de Janeiro, RJ: Imago. (Trabalho original publicado em 1913)

Freud, S. (2006). História de uma neurose infantil. In S. Freud, Edição standard das obras psicológicas completas de Sigmund Freud (Vol. 12, pp. 19-127). Rio de Janeiro, RJ: Imago. (Trabalho original publicado em 1918)

Freud, S. (2006). Além do princípio de prazer. In S. Freud, Edição standard das obras psicológicas completas de Sigmund Freud (Vol. 18, pp. 17-75). Rio de Janeiro, RJ: Imago. (Trabalho original publicado em 1920)

Herzog, R., \& Gondar, J. (2011). Materialismo e realidade: de Freud a Ferenczi. In A. C. Lo Bianco (Org.), A materialidade da psicanálise (pp. 27-39). Rio de Janeiro, RJ: Contra Capa.

Lacan, J. (2005). O seminário, livro 10: a angústia. Rio de Janeiro, RJ: Jorge Zahar. (Trabalho original publicado em 1962-1963)

Lorin, C. (1982). Le jeune Ferenczi. Paris: Aubier Montaigne. Sabourin, P. (1988). Ferenczi, paladino e grão-vizir secreto. São Paulo, SP: Martins Fontes. 